\title{
Distributional records of Antarctic fungi based on strains preserved in the Culture Collection of Fungi from Extreme Environments (CCFEE) Mycological Section associated with the Italian National Antarctic Museum (MNA)
}

\author{
Laura Selbmann ${ }^{4}$, Silvano Onofri ${ }^{4}$, Laura Zucconi ${ }^{4}$, Daniela Isola ${ }^{2}$, \\ Marino Rottigni ${ }^{1,2}$, Claudio Ghiglione ${ }^{1,3}$, Paola Piazza ${ }^{1,2}$, \\ Maria Chiara Alvaro ${ }^{1,2}$, Stefano Schiaparelli ${ }^{1,2}$
}

I Italian National Antarctic Museum (MNA, Section of Genoa), University of Genoa, Genoa, Italy 2 Department of Earth, Environmental and Life Sciences (DISTAV), University of Genoa, Genoa, Italy 3 Department of Physical, Earth and Environmental Sciences, University of Siena, Siena, Italy 4 Department of Ecological and Biological Sciences (DEB), Tuscia University, Viterbo, Italy

Corresponding author: Stefano Schiaparelli (stefano.schiaparelli@unige.it)

Academic editor: C.L. Schoch | Received 21 May 2015 | Accepted 26 June 2015 | Published 16 July 2015

Citation: Selbmann L, Onofri S, Zucconi L, Isola D, Rottigni M, Ghiglione C, Piazza P, Alvaro MC, Schiaparelli S (2015) Distributional records of Antarctic fungi based on strains preserved in the Culture Collection of Fungi from Extreme Environments (CCFEE) Mycological Section associated with the Italian National Antarctic Museum (MNA). MycoKeys 10: 57-71. doi: 10.3897/mycokeys. 10.5343

Resource citation: Italian National Antarctic Museum (2015-). Distributional records of Antarctic Fungi based on strains preserved in the Culture Collection of Fungi from Extreme Environments (CCFEE), Mycological Section associated with the Italian National Antarctic Museum (MNA). Contributed by: Laura Selbmann, Silvano Onofri, Laura Zucconi, Daniela Isola, Marino Rottigni, Claudio Ghiglione, Paola Piazza, Maria Chiara Alvaro, Stefano Schiaparelli. Online at http://ipt.biodiversity.aq/manage/resource-registerResource.do. GBIF key: http://www.gbif.org/dataset/65e34334-66b3$4536-\mathrm{ac} 3 \mathrm{c}-857893 \mathrm{fe} 0 \mathrm{f} 6 \mathrm{a}$

\begin{abstract}
This dataset includes information regarding fungal strains collected during several Antarctic expeditions: the Italian National Antarctic Research program (PNRA) expeditions "X" (1994/1995), "XII" (1996/1997), “XVII” (2001/2002), “XIX” (2003/2004), “XXVI” (2010/2011), the Czech "IPY Expedition" (2007-2009) and a number of strains donated by E. Imre Friedmann (Florida State University) in
\end{abstract}

Copyright Laura Selbmann et al. This is an open access article distributed under the terms of the Creative Commons Attribution License (CC BY 4.0), which permits unrestricted use, distribution, and reproduction in any medium, provided the original author and source are credited. 
2001, isolated from samples collected during the U.S.A. Antarctic Expeditions of 1980-1982. Samples, consisting of colonized rocks, mosses, lichens, sediments and soils, were collected in Southern and Northern Victoria Land of the continental Antarctica and in the Antarctic Peninsula. A total of 259 different strains were isolated, belonging to 32 genera and 38 species, out of which 12 represented new taxa. These strains are preserved in the Antarctic section of the Culture Collection of Fungi from Extreme Environments (CCFEE), which represents one of the collections associated with the Italian National Antarctic Museum (MNA, Section of Genoa, Italy), located at the Laboratory of Systematic Botany and Mycology, Department of Ecological and Biological Sciences (DEB), Tuscia University (Viterbo, Italy). The CCFEE hosts a total of 486 Antarctic fungal strains from worldwide extreme environments. Distributional records are reported here for 259 of these strains. The holotypes of the 12 new species included in this dataset are maintained at CCFEE and in other international collections: CBS-KNAW Fungal Biodiversity Centre (Utrecht, Netherlands); DBVPG, Industrial Yeasts Collection (University of Perugia, Italy); DSMZ, German Collection of Microorganisms and Cell Cultures (Brunswick, Germany); IMI, International Mycological Institute (London, U.K.).

\section{Key words}

Antarctica, Antarctic Peninsula, CCFEE, Fungi, MNA, Victoria Land

\section{Purpose}

The aim of this study is to provide new distributional data on Antarctic fungi collected in the framework of past and recent expeditions (Italian PNRA, USA and Czech expeditions) and now preserved in the Antarctic section of the Culture Collection of Fungi From Extreme Environments (CCFEE - Antarctic Fungi), a collection associated with the Italian Antarctic National Museum (MNA, Section of Genoa, Italy). CCFEE is located at the Laboratory of Systematic Botany and Mycology, Department of Ecological and Biological Sciences (DEB) of the Tuscia University (Viterbo, Italy).

The dataset is the third Italian contribution to ANTABIF based on materials stored at the Italian National Antarctic Museum (MNA) and in its associated collections. The first MNA dataset published regarded the distributional records of Antarctic Mollusca, collected in the framework of the Latitudinal Gradient Program (Ghiglione et al. 2013), while the second MNA dataset regarded the distributional records of Antarctic Tanaidaceans collected in the Ross Sea (Piazza et al. 2014).

\section{Project details}

Project title: Antarctic Fungi from museum samples preserved in the Culture Collection of Fungi From Extreme Environments (CCFEE - Antarctic Fungi), which is a collection associated with the Italian National Antarctic Museum (MNA, Section of Genoa, Italy) hosted in the Laboratory of Systematic Botany and Mycology, Dept of Ecological and Biological Sciences (DEB), Tuscia University (Viterbo, Italy).

Curator and Promoter: Stefano Schiaparelli 
Personnel: Laura Selbmann, Silvano Onofri, Laura Zucconi, Daniela Isola, Marino Rottigni, Claudio Ghiglione, Paola Piazza, Maria Chiara Alvaro, Stefano Schiaparelli.

Funding: The fungal strains were isolated from substrata (soils, sediments, mosses, lichens and rocks) sampled as part of different research projects funded by the Italian National Antarctic Research Program (PNRA), the National Science Foundation (NSF) of U.S.A. and Czech Ministry of Education, Youth and Sports, as listed below:

- PNRA X expedition (1994/1995) - Project 2d.1c ("Ecological and genetic aspects of population differentiation");

- PNRA XII expedition (1996/1997) - Project 2c.3.1 (“Antarctic Biology: biodiversity, evolutionary strategies and colonization");

- PNRA XVII expedition (2001/2002) - Project 2002/1.3 (“Antarctic terrestrial and freshwater ecosystems: response to latitudinal variations of climatic and environmental conditions");

- PNRA XIX expedition (2003/2004) - Project 2002/1.3 (“Antarctic terrestrial and freshwater ecosystems: response to latitudinal variations of climatic and environmental conditions");

- PNRA XXVI expedition (2010/2011) - Project 2009/A1.11 ("Biodiversity and evolution of polar rocks' meristematic fungi: potential bioindicators of global changes and anthropogenic impacts");

- Czech IPY expedition (2007-2009) - Projects ME-945 KONTAKT and MSM 0021622416 ("Multidisciplinary study of Antarctic terrestrial vegetation within the IPY framework");

The collection also includes a number of strains donated by E. Imre Friedmann (Florida State University) in 2001, isolated from samples collected during the U.S.A. Antarctic Expeditions (1980-1982).

Study area description: Samples from which strains were isolated were collected in Southern and Northern Victoria Land, McMurdo Dry Valleys and the Antarctic Peninsula, from sea level up to 3400 m a.s.l. (Archambault Ridge, Antarctica).

\section{Temporal coverage and coordinates:}

PNRA X expedition (1994/1995): latitude from -76.91667 to -72.63333 ; longitude from 160.91667 to 169.36667

PNRA XII expedition (1996/1997): latitude from -74.06667 to -76.91775 ; longitude from 158.03517 to 165.31667

PNRA XVII expedition (2001/2002): latitude from -62.09139 to -74.88333 ; longitude from -58.45 to 163.71667

PNRA XIX expedition (2003/2004): latitude from -78.91075 to -72.71194 ; longitude from 159.04619 to 166.61667

PNRA XXVI expedition (2010/2011): latitude from -76.91000 to -73.44611; longitude from 159.18194 to 165.31667

U.S.A. expeditions (1980-1982): latitude from -77.86667 to -77.5 ; longitude from 160.66667 to 162 
Czech expeditions (2007-2009): latitude -63.8; longitude -57.88333

Design description: Data were gathered by assembling distributional records of Antarctic fungal strains stored in the CCFEE. Samples from which all the strains were isolated were obtained in the framework of different past research expeditions, which had different aims and geographical targets. The main purpose of PNRA " $\mathrm{X}$ " expedition was to evaluate the adaptation of microfungal strains to low temperatures, thermal stress, desiccation and exposure to radiation. During the "XII", "XVII" and "XIX" PNRA expeditions, the projects aimed at collecting rock samples for studying the biology and biodiversity of fungi from cryptoendolithic communities in the sandstone formations of several continental Antarctic coastal, and inland locations and from Antarctic Peninsula, as well as their role in the alteration of the rock substrate. The project developed in the framework of the "XXVI" PNRA expedition aimed at studying responses of rock meristematic fungi to environmental stresses related with the global change, and their role in the bioaccumulation and biomagnification processes of contaminants in the trophic networks. The main purpose of the Czech expedition was to study fungal biodiversity from soil and rock samples collected in the Antarctic Peninsula. The U.S.A. expeditions aimed at studying the biology and diversity of cryptoendolithic communities of the McMurdo Dry Valleys, and monitoring nanoclimate variations within the rock substrate.

\section{Methods}

Method step description: See sampling description below and flowchart of Figure 1. Study extent description: The distributional data herein considered refer to 53 different locations (Figure 2a, 2b, 2c), located along the Victoria Land (continental Antarctica) and the Antarctic Peninsula. Samples from which fungi were isolated were collected in the framework of the following expeditions, from 1980 to 2011:

- PNRA X expedition: samples of soil, mosses, lichens, rocks and sediments were collected from lake area near Camp OASI, Skua Lake, Tethys Bay, Enigma Lake, Vegetation Island, Inexpressible Island, Starr Nunatak, Edmonson Point, Baker Rocks, Kay Island, Mt Melbourne. In particular, in the site called Cryptogam Ridge, above the Mt. Melbourne volcanic cone, a small quantity of soil has been sampled for isolating thermophilic fungal strains and studying the fungal diversity of the area;

- PNRA XII expedition: samples of colonized sandstone were collected from Battleship Promontory, Mt Billing, Mt Howard, Trio Nunataks, Richards Nunatak, Timber Peak. Other sites have been visited to collect different types of rock samples as granites (BTN Base, Camp Antenne, Tethys Bay, Gondwana Station, O'Kane Glacier, Vegetation Island, Inexpressible Island, Boomerang Glacier, Collins Peak, Mt Crummer), pegmatite (Inexpressible Island, Boomerang Glacier), and sienite at Vegetation Island; 


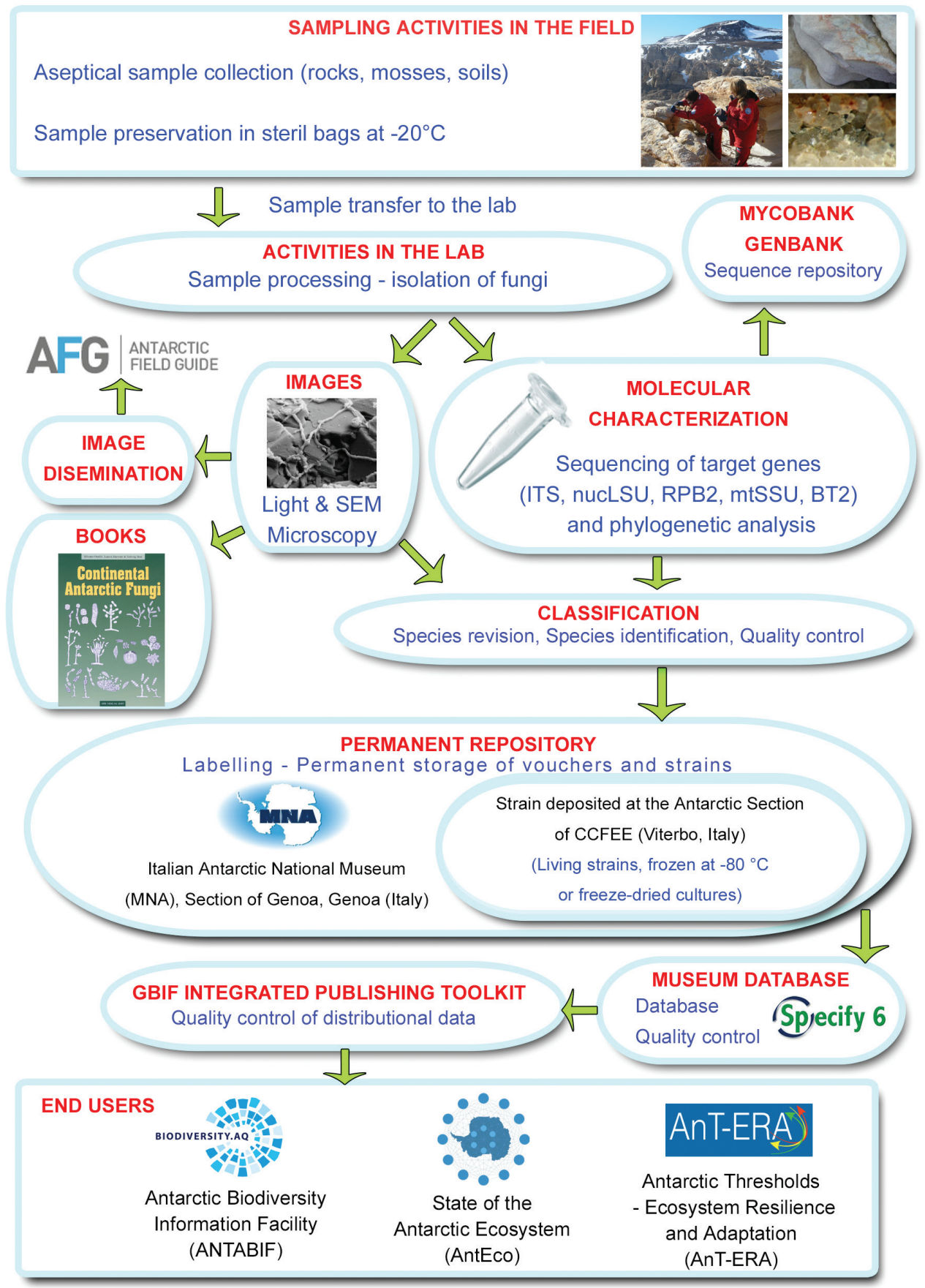

Figure I. Flowchart depicting major steps in dataset development and publishing. 


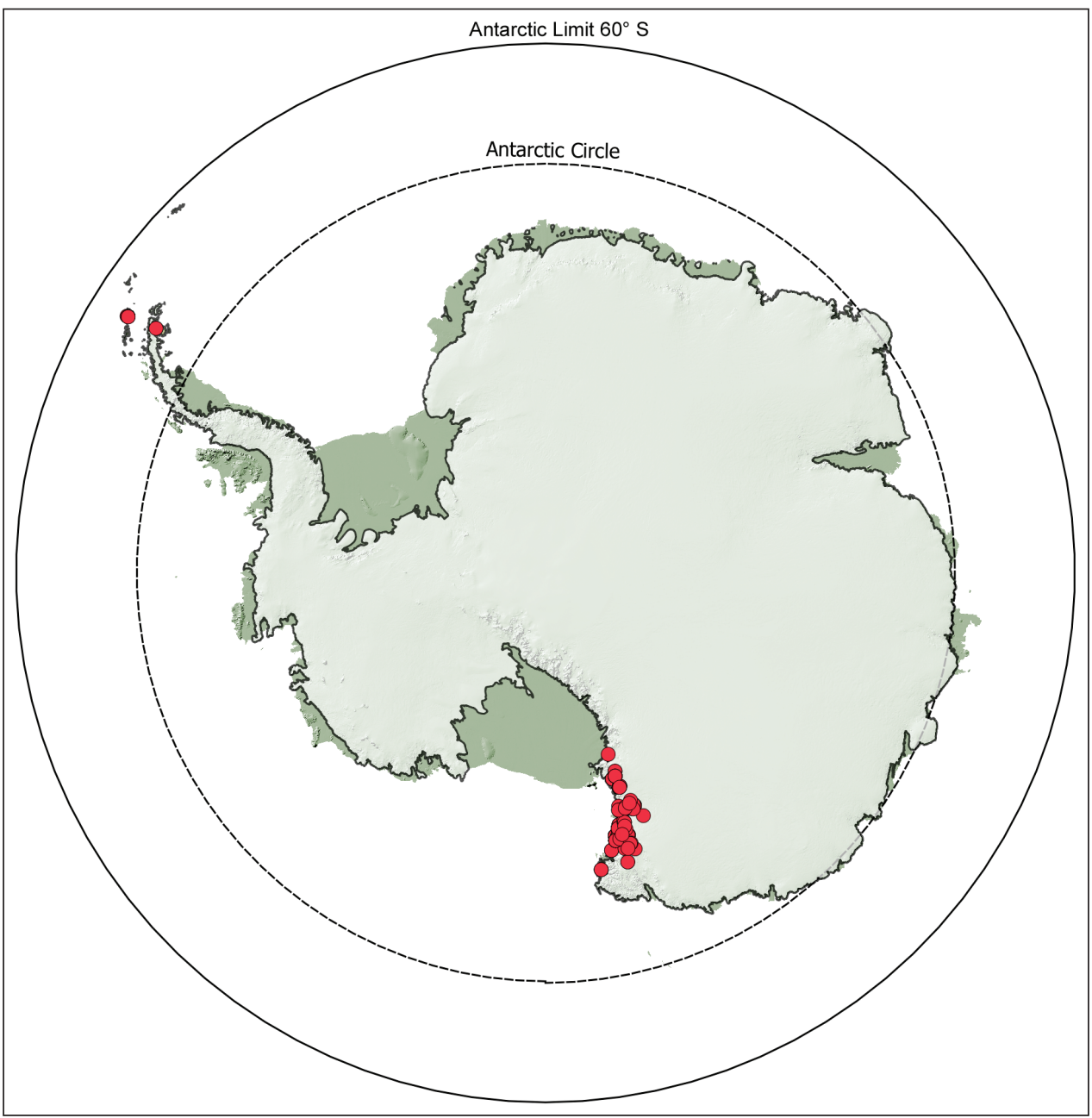

Figure 2a. Map of sampling stations.

- PNRA XVII expedition: different rock samples were collected in the Antarctic Peninsula starting from the Polish base Arctowski, King George Island;

- PNRA XIX expedition: sampling activities were carried out at Baker Rocks, Campo Icaro, Cape King, Edmonson Point, Ford Peak, Gondwana Lake, Harrow Peak, Inexpressible Island, Kay Island, Lichen Hills, Morris Basin (Ricker Hills), Starr Nunatak, Tarn Flat, Vegetation Island, and Widowmaker Pass in Northern Victoria Land, and Battleship Promontory, Convoy Range, Linnaeus Terrace, and University Valley in the McMurdo Dry Valleys, Southern Victoria Land;

- PNRA XXVI expedition: sampling was performed through latitudinal transect from $73^{\circ} 26^{\prime} 47^{\prime \prime}$, at Chisholm Hills (Cosmonaut Glacier), to 7654'36"S, at Battleship Promontory, in a altitudinal gradient, from the sea level to $3400 \mathrm{~m}$ of Mount Adamson and, in a longitudinal gradient, from the coast to the inland; 


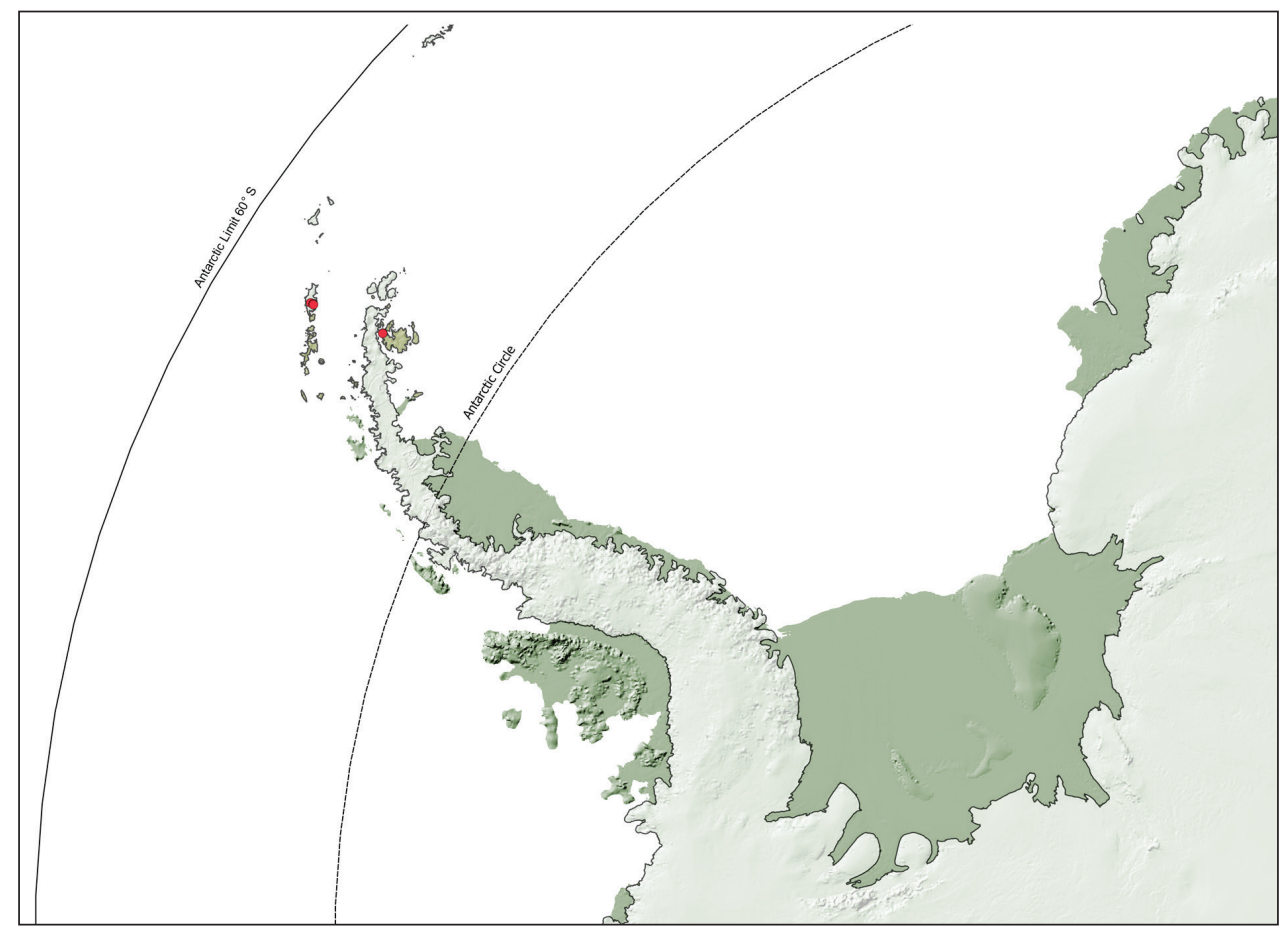

Figure 2b. Map of sampling stations. Zoom for the Antarctic Peninsula area.

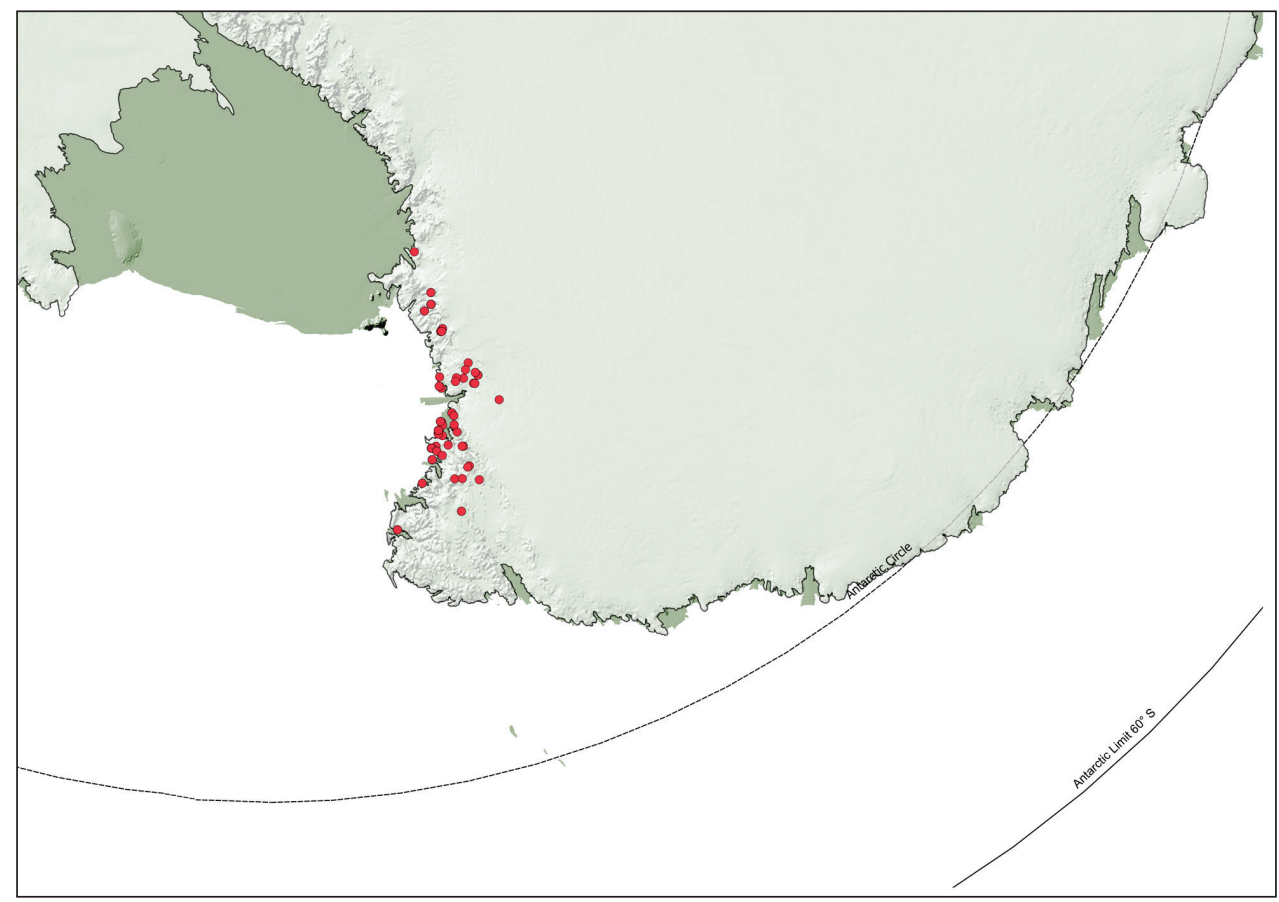

Figure 2c. Map of sampling stations. Zoom for the Ross Sea area. 
all the sandstone's formations and some granite formations of Northern Victoria Land were visited;

- Czech IPY expedition: sampling was performed in the Antarctic Peninsula. Black meristematic fungi were isolated in Masaryk University, Brno, Czech Republic and donated to the CCFEE;

The U.S.A. expeditions: aimed to study the biology and diversity of cryptoendolithic communities of the McMurdo Dry Valleys, and sampling was performed in that area. Black meristematic fungi isolated were donated to the CCFEE.

Sampling description: The materials were collected by hand and, whenever needed, by using hammer and chisel in order to chop rock fragments from large boulders.. Samples were then placed in sterile plastic bags and stored at $-20{ }^{\circ} \mathrm{C}$ (Figure 1). Fungi from rocks were isolated by crushing stones and plating fragments directly on Petri dishes containing Malt Agar (MA) amended with chloramphenicol 100 ppm; plates were incubated at $10{ }^{\circ} \mathrm{C}$ and growth was inspected monthly.

Isolation from lichens was performed according to Selbmann et al. (2013). Isolation from other sediments, soils, and mosses was performed by diluting $1 \mathrm{~g}$ of each substrate in 11 of sterile water and plating $100 \mu$ of the suspension in a $9 \mathrm{~cm}$ Petri dish containing MA or Czapek dox agar (CZA). Plates were incubated at 10 and $25^{\circ} \mathrm{C}$ and growth inspected every day. Colonies were transferred in fresh medium immediately after their appearance and identified by macro- and microscopic observations. Scanning electron microscopy observations were performed according to the methods described by Onofri et al. (1980). When morphology was not informative enough for identification, the isolates were studied with a molecular approach according to Selbmann et al. (2005; 2008). Fungi were identified by Selbmann, Onofri, Zucconi and Isola.

All the isolates are preserved in the Culture Collection of Fungi from Extreme Environments (CCFEE). All the fungi are preserved as living $\left(\right.$ at $4{ }^{\circ} \mathrm{C}$ ), frozen (at $-80{ }^{\circ} \mathrm{C}$ ) or freeze-dried cultures, or as dry samples. Holotype materials are deposited at: CBS-KNAW Fungal Biodiversity Centre (Utrecht, Netherlands); Industrial Yeasts Collection (Perugia, Italy); German Collection of Microorganisms and Cell Cultures (Brunswick, Germany); International Mycological Institute (London, United Kingdom) (Table.1). Ex-types of newly described taxa are preserved in the CCFEE.

The present dataset of Antarctic fungi has been formatted in order to fulfil Darwin Core standards required by the IPT scheme, according the GBIF Data Toolkit (http:// www.gbif.org/resources/2573). The dataset was uploaded in the ANTABIF database (the geospatial component of GBIF).

Quality control description: Strains were identified by both morphological and molecular tools. DNA sequence data obtained from the studied strains are deposited in Mycobank and GenBank. Species names were crosschecked and made consistent with current ones as reported in MycoBank (last check made on 2015.08.04) (Figure 1). Distributional records' geographical coordinates are as published in the different papers reported in the reference section. During the more recent expeditions (XIX and XXVI) the coordinates were recorded using a Garmin GPS. 


\begin{tabular}{|c|c|c|c|c|c|c|c|c|c|c|c|c|}
\hline 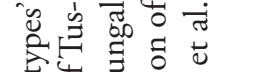 & $\mid \begin{array}{l}\ddot{\Xi} \\
\tilde{\Xi}\end{array}$ & - & $n$ & - & - & $\tau$ & $m$ & $N$ & - & $\forall$ & $n$ & m \\
\hline 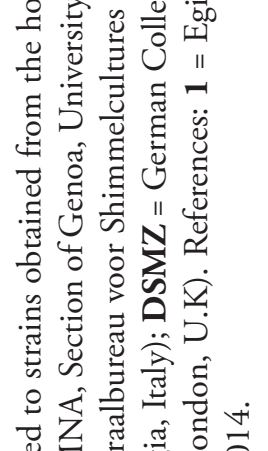 & 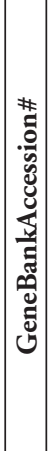 & 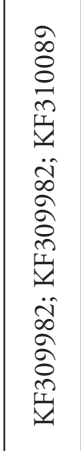 & 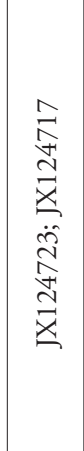 & 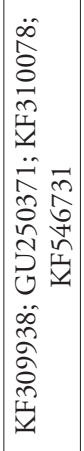 & 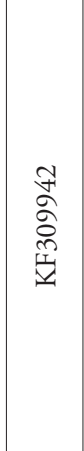 & 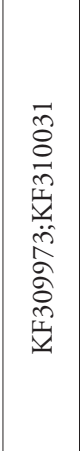 & 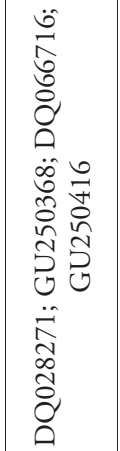 & $\begin{array}{l}\text { जे } \\
\text { ñ } \\
\infty \\
\infty \\
\end{array}$ & 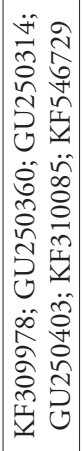 & 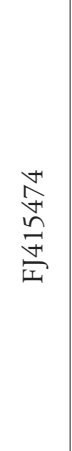 & 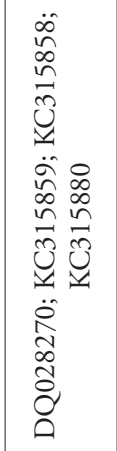 & 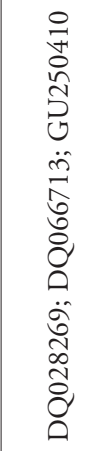 \\
\hline 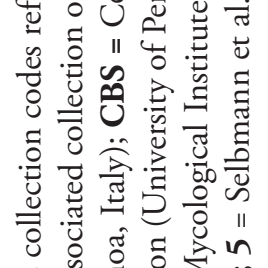 & 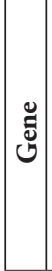 & 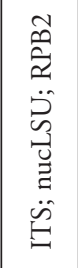 & 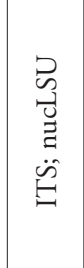 & 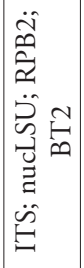 & 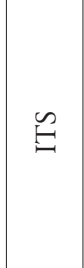 & 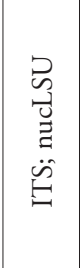 & 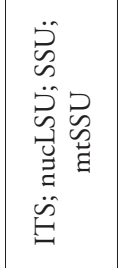 & $\mathscr{E}$ & 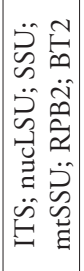 & $\tilde{E}$ & 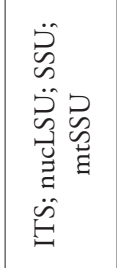 & $\begin{array}{l}D \\
\tilde{n} \\
\ddot{E} \\
\ddot{n} \\
\ddot{n} \\
\ddot{n} \\
\ddot{n}\end{array}$ \\
\hline 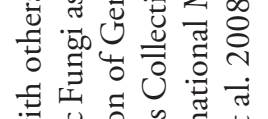 & 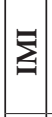 & & & & & & & 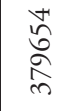 & & & & \\
\hline 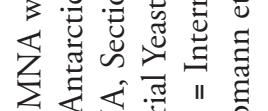 & $\begin{array}{l}N \\
\sum \\
\\
\end{array}$ & & $\begin{array}{l}n \\
\stackrel{\infty}{+} \\
\stackrel{+}{N}\end{array}$ & & & & & & & & & \\
\hline 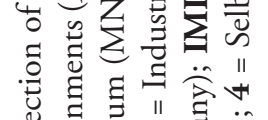 & 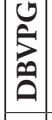 & & \begin{tabular}{l}
$\infty$ \\
\multirow{N}{*}{} \\
\multirow{n}{*}{}
\end{tabular} & & & & & & & & & \\
\hline 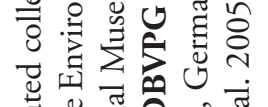 & 望 & 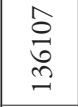 & $\underset{n}{n}$ & 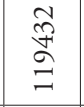 & & 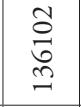 & $\stackrel{\substack{\hat{\kappa} \\
ٍ}}{=}$ & & $\underset{\substack{0 \\
0}}{n}$ & 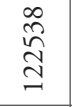 & 苂 & 家 \\
\hline 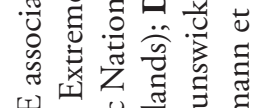 & z & $\begin{array}{l}\infty \\
\stackrel{0}{+} \\
\substack{1 \\
1}\end{array}$ & 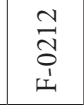 & \begin{tabular}{l}
\multirow{2}{1}{} \\
o \\
1 \\
1
\end{tabular} & 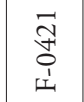 & 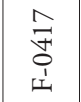 & $\begin{array}{l}\infty \\
\stackrel{\infty}{0} \\
0 \\
1 \\
1\end{array}$ & $\begin{array}{l}\text { तี } \\
\text { ô. } \\
\text { 1. }\end{array}$ & 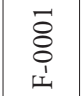 & \begin{tabular}{l} 
त̂ \\
\multirow{2}{1}{} \\
1
\end{tabular} & $\begin{array}{l}\text { ô } \\
\text { o } \\
1 \\
\text { L }\end{array}$ & 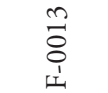 \\
\hline 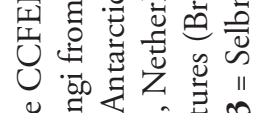 & 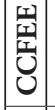 & 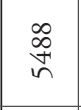 & $\stackrel{\infty}{\stackrel{\infty}{n}}$ & $\underset{\sim}{\approx}$ & $\begin{array}{l}\hat{\sim} \\
\tilde{n}\end{array}$ & $\stackrel{\widetilde{n}}{n}$ & $\underset{\infty}{\infty}$ & 总 & $\vec{\hbar}$ & $\stackrel{m}{n}$ & $\underset{\infty}{\stackrel{\infty}{\vec{n}}}$ & $\stackrel{\star n}{n}$ \\
\hline 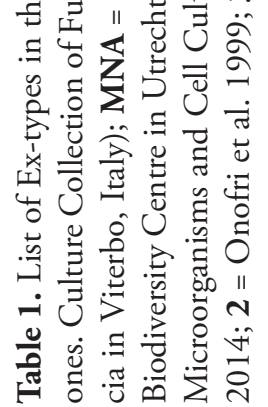 & $\mid$ & 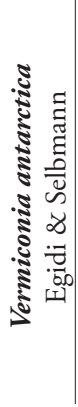 & 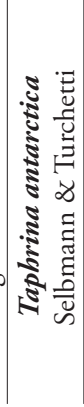 & 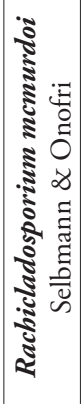 & 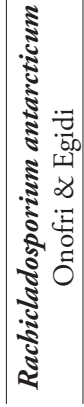 & 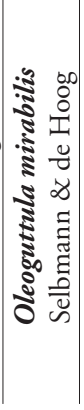 & 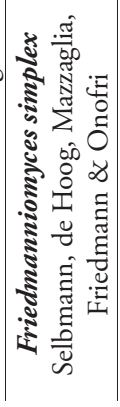 & 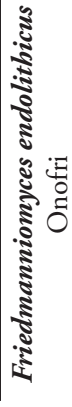 & 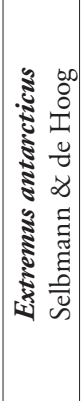 & 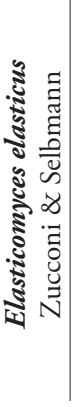 & 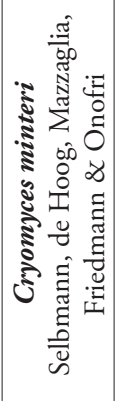 & 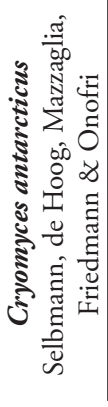 \\
\hline
\end{tabular}




\section{Taxonomic coverage}

General taxonomic coverage description: Fungal assemblages in Antarctic rocks have been extensively studied with particular emphasis for free-living but also symbiotic fungal populations, which constitute an important part of epilithic and endolithic communities (Selbmann et al. 2014). The interest for these communities is strongly connected to their high adaptability to the Antarctic ice-free environmental conditions, a combination of extremely low temperatures, low water activity, oligotrophy and high solar irradiation; for these reasons they constitute a useful model for studying evolution and adaptations to extreme environments. On the whole, this dataset takes into account 259 fungal strains, out of the 486 available at CCFEE. This initial dataset corresponds to the species that have been well characterized from a taxonomic point of view and have all the metadata required by Darwin Core for publication as distributional records. They belong to three Divisions, i.e. Ascomycota, Basidiomycota and Mucoromycotina (Figure 3), corresponding to a total of 32 genera (Figure 4) and 38 species. Among them, the $93 \%$ belong to Ascomycota Phylum, that includes the almost totality of genera and the totality of new taxa present in the collection (12 species and 6 genera) (Table 1). One basidiomycetous new species, isolated from soil under moss in Kay Island, Cryptococcus vaughanmartiniae Turchetti, Blanchette \& Arenz (CCFEE5495=DBVPG5862), was recently described (Turchetti et al. 2015).

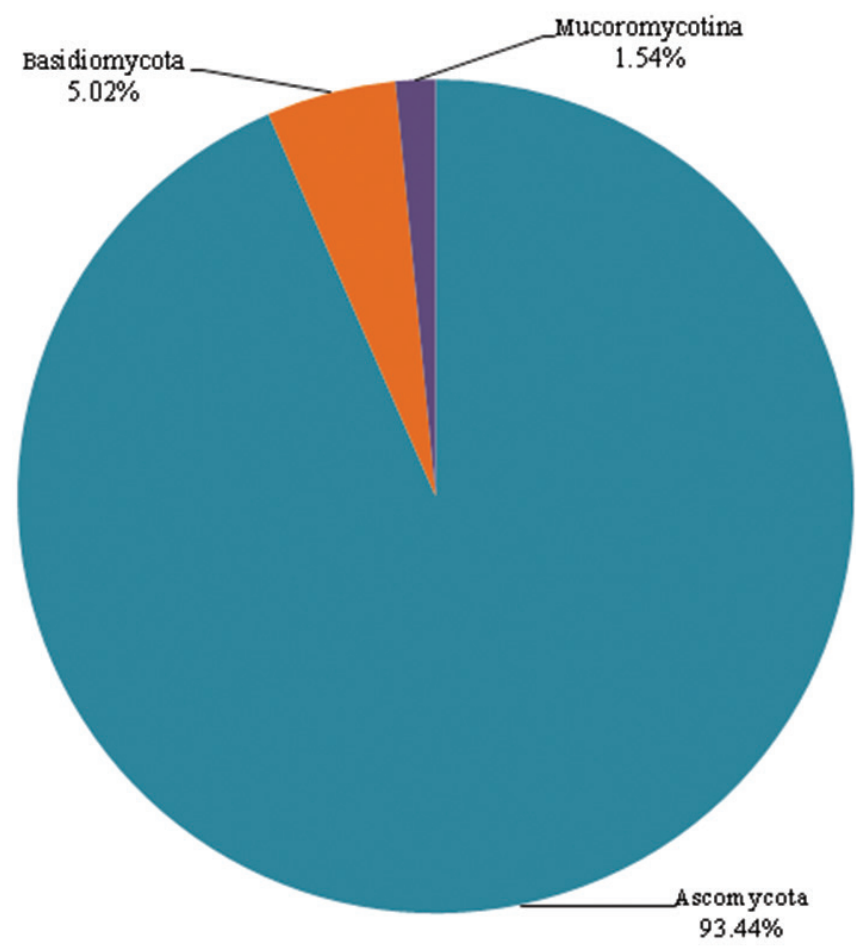

Figure 3. Taxonomic coverage (percentage per Division) of MNA Fungi Collection 


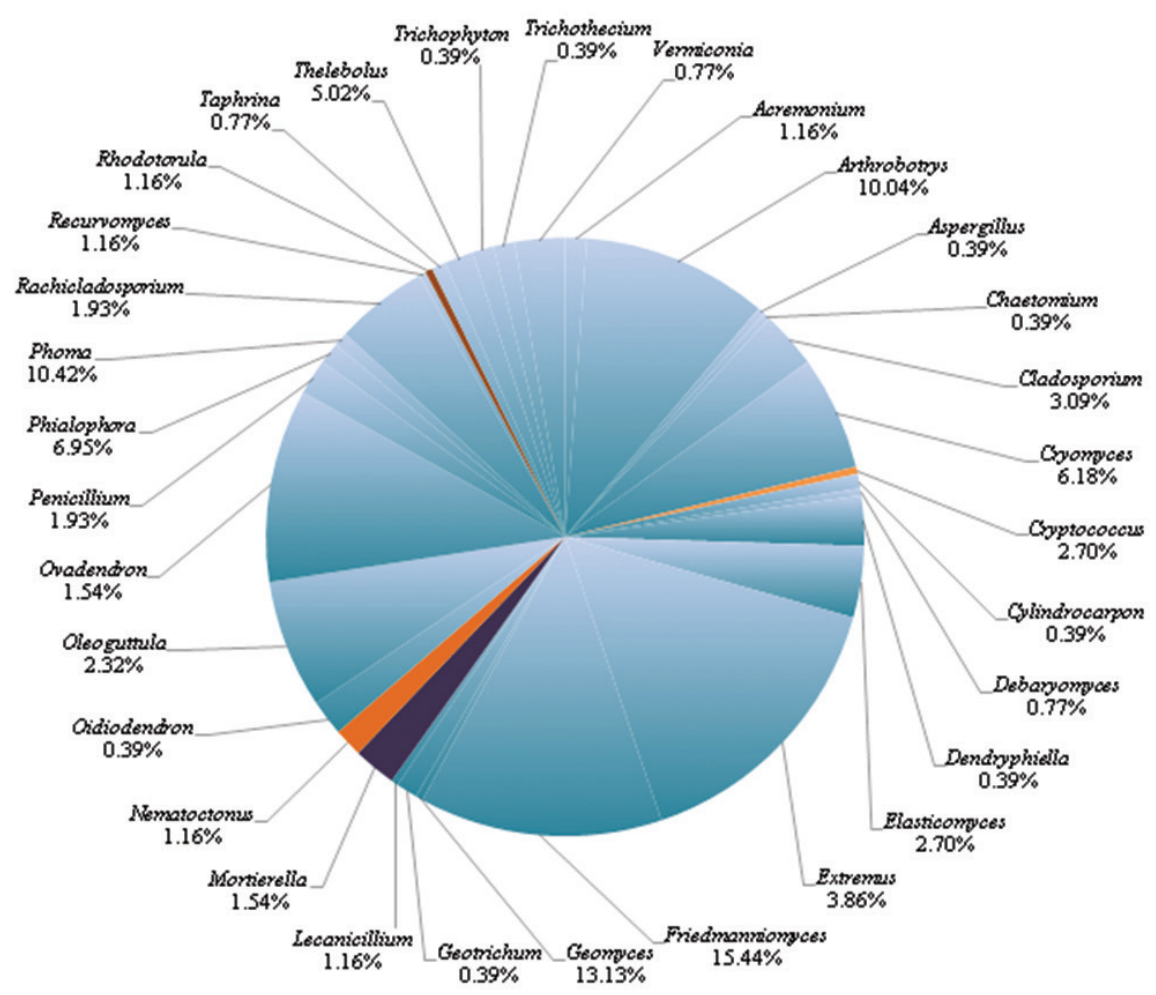

Figure 4. Taxonomic coverage (percentage per Genus) of MNA Fungi Collection.

\section{Taxonomic ranks}

Kingdom: Fungi

Division: Ascomycota

Genus: Acremonium, Arthrobotrys, Aspergillus, Chaetomium, Cladosporium, Cryomyces, Cylindrocarpon, Debaryomyces, Dendryphiella, Elasticomyces, Extremus, Friedmanniomyces, Geomyces, Geotrichum, Lecanicillium, Oidiodendron, Oleoguttula, Ovadendron, Penicillium, Phialophora, Phoma, Rachicladosporium, Recurvomyces, Taphrina, Thelebolus, Trichophyton, Trichothecium, Vermiconia

Species: Acremonium berkeleyanum; Arthrobotrys ferox; Arthrobotrys sp., Aspergillus versicolor; Chaetomium sp.; Cladosporium cladosporioides; Cladosporium herbarum; Cladosporium sp.; Cryomyces antarcticus; Cryomyces minteri; Cylindrocarpon didymum; Debaryomyces hanseni; Dendryphiella salina; Elasticomyces elasticus; Extremus antarcticus; Friedmanniomyces endolithicus; Friedmanniomyces simplex; Geomyces pannorum; Geomyces sp.; Geotrichum candidum; Lecanicillium muscarium; Oidiodendron griseum; Oleoguttula mirabilis; Oleoguttula sp.; Ovadendron sulphureoochraceum; Penicillium sp.; Penicillium viridicatum; Phialophora fastigiata; Phialophora malorum; Phialophora sp.; Phoma herbarum; Phoma sp.; Rachicladosporium antarcticum; Rachicladosporium momurdoi; Rachicladosporium sp.; Recurvomyces 
mirabilis; Taphrina antarctica; Thelebolus microsporus; Trichophyton terrestre; Trichothecium roseum; Vermiconia antarctica

Division: Basidiomycota

Genus: Cryptococcus, Nematoctonus, Rhodotorula

Species: Cryptococcus antarcticus; Cryptococcus friedmannii; Cryptococcus victoriae; Cryptococcus vishniacii; Nematoctonus sp.; Rhodotorula mucilaginosa; Rhodotorula sp.

Division: Mucoromycotina

Genus: Mortierella

Species: Mortierella alpina; Mortierella sp.

\section{Natural collections description}

Parent collection identifier: Italian National Antarctic Museum (MNA Section of Genoa, Italy), and Antarctic Section of the Culture Collection of Fungi from Extreme Environments (CCFEE), Mycological Section of MNA, Laboratory of Systematic Botany and Mycology, Dept of Ecological and Biological Sciences (DEB), Tuscia University (Viterbo, Italy).

Collection name: MNA (Section of Genoa) associated collection of Culture Collection of Fungi From Extreme Environments (CCFEE) - Antarctic Fungi

Collection identifier: http://www.mna.it; http://www.sma.unitus.it/

Specimen preservation method: Strains are stored and maintained as living cultures on Agar slant at $4{ }^{\circ} \mathrm{C}$, frozen at $-80^{\circ} \mathrm{C}$, freeze dried, or as dry samples.

\section{Datasets}

Dataset description: This dataset contains data from the Kingdom Fungi, Division Ascomycota, Basidiomycota and Mucoromycotina, from Victoria Land. In total it includes 38 different species of fungi for a total of 259 individuals. The Darwin Core elements included in the dataset are: catalogue number (i.e. MNA catalogue number), scientific name, expedition/station, gear, date collected, decimal latitude, decimal longitude, depth, individual count, institution code (i.e. name of institution where the samples are kept), collection code (i.e. MNA acronym) and status.

Object name: MNA (Section of Genoa) associated collection of CCFEE (Tuscia University) - Antarctic Fungi

Character encoding: UTF-8

Format name: Darwin Core Archive format

Format version: 1.0

Distribution: http://ipt.biodiversity.aq/resource.do?r=aaa

Language: English

Metadata language: English 
License of use: This dataset [MNA (Section of Genoa) associated collection of CCFEE (Tuscia University) - Antarctic Fungi] is made available under the Open Data Commons Attribution License: http://www.opendatacommons.org/license/by/1.0

Date of metadata creation: April 8, 2015

Hierarchy level: Dataset

\section{Acknowledgements}

We are indebted to Cecile Gueidan (Australian National Herbarium) for the comments on a previous version of the MS.

\section{References}

\section{References cited in the text}

Ghiglione C, Alvaro MC, Griffiths HJ, Linse K, Schiaparelli S (2013) Ross Sea Mollusca from the Latitudinal Gradient Program: R/V Italica 2004 Rauschert dredge samples. ZooKeys 341: 37-48. doi: 10.3897/zookeys.341.6031

Onofri S, Castagnola M, Rossi Espagnet S (1980) Use of Scanning Electron Microscopy (SEM) in mycology. Micologia Italiana 1: 29-32.

Piazza P, Blazewicz-Paszkowycz M, Ghiglione C, Alvaro MC, Schnabel K, Schiaparelli S (2014) Distributional records of Ross Sea (Antarctica) Tanaidacea from museum samples stored in the collections of the Italian National Antarctic Museum (MNA) and the New Zealand National Institute of Water and Atmospheric Research (NIWA). ZooKeys 451: 49-60. doi: 10.3897/zookeys.451.8373

Selbmann L, Zucconi L, Onofri S, Cecchini C, Isola D, Turchetti B, Buzzini P (2014) Taxonomic and phenotypic characterization of yeasts isolated from worldwide cold rock-associated habitats. Fungal Biology 118: 61-71. doi: 10.1016/j.funbio.2013.11.002

Selbmann L, Grube M, Onofri S, Isola D, Zucconi L (2013) Antarctic epilithic lichens as niches for black meristematic fungi. Biology 2: 784-797. doi: 10.3390/biology2020784

Selbmann L, de Hoog GS, Zucconi L, Isola D, Ruisi S, den Ende AHGG, Ruibal C, De Leo F, Urzi C, Onofri S (2008) Drought meets acid: three new genera in a dothidealean clade of extremotolerant fungi. Studies in Mycology: 1-20. doi: 10.3114/sim.2008.61.01

Selbmann L, de Hoog GS, Mazzaglia A, Friedmann EI, Onofri S (2005) Fungi at the edge of life: cryptoendolithic black fungi from Antarctic desert. Studies in Mycology: 1-32.

Turchetti B, Selbmann L, Blanchette RA, Di Mauro S, Marchegiani E, Zucconi L, Arenz BE, Buzzini P (2015). Cryptococcus vaughanmartiniae sp. nov. and Cryptococcus onofrii sp. nov.: two new species isolated from worldwide cold environments. Extremophiles, 19: 149-159. doi: $10.1007 / \mathrm{s} 00792-014-0692-3$

\section{References based on this dataset}

de Vera JP, Boettger U, Noetzel RD, Sanchez FJ, Grunow D, Schmitz N, Lange C, Hubers HW, Billi D, Baque M, Rettberg P, Rabbow E, Reitz G, Berger T, Moller R, Bohmeier 
M, Horneck G, Westall F, Janchen J, Fritz J, Meyer C, Onofri S, Selbmann L, Zucconi L, Kozyrovska N, Leya T, Foing B, Demets R, Cockell CS, Bryce C, Wagner D, Serrano P, Edwards HGM, Joshi J, Huwe B, Ehrenfreund P, Elsaesser A, Ott S, Meessen J, Feyh N, Szewzyk U, Jaumann R, Spohn T (2012) Supporting Mars exploration: BIOMEX in Low Earth Orbit and further astrobiological studies on the Moon using Raman and PanCam technology. Planetary and Space Science 74: 103-110. doi: 10.1016/j.pss.2012.06.010

Egidi E, de Hoog GS, Isola D, Onofri S, Quaedvlieg W, de Vries M, Verkley GJM, Stielow JB, Zucconi L, Selbmann L (2014) Phylogeny and taxonomy of meristematic rock-inhabiting black fungi in the Dothideomycetes based on multi-locus phylogenies. Fungal Diversity 65: 127-165. doi: 10.1007/s13225-013-0277-y

Hubka V, Reblova M, Rehulka J, Selbmann L, Isola D, de Hoog SG, Kolarik M (2014) Bradymyces gen. nov (Chaetothyriales, Trichomeriaceae), a new ascomycete genus accommodating poorly differentiated melanized fungi. Antonie Van Leeuwenhoek International Journal of General and Molecular Microbiology 106: 979-992. doi: 10.1007/s10482014-0267-4

Onofri S, de la Torre R, de Vera JP, Ott S, Zucconi L, Selbmann L, Scalzi G, Venkateswaran KJ, Rabbow E, Inigo FJS, Horneck G (2012) Survival of Rock-Colonizing Organisms After 1.5 Years in Outer Space. Astrobiology 12: 508-+. doi: 10.1089/ast.2011.0736

Onofri S, Selbmann L, Barreca D, Isola D, Zucconi L (2009) Fungal survival in space conditions: new insights for lithopanspermia. Plant Biosystems 143: S85-S87. doi: 10.3114/ sim.2008.61.10

Onofri S, Barreca D, Selbmann L, Isola D, Rabbow E, Horneck G, De Vera J, Hatton J, Zucconi L (2008) Resistance of Antarctic black fungi and cryptoendolithic communities to simulated space and Martian conditions. Studies in Mycology 61: 99-109.

Onofri S, Zucconi L, Tosi S (2007) Continental antarctic fungi.

Onofri S, Selbmann L, Zucconi L, Pagano S (2004) Antarctic microfungi as models for exobiology. Planetary and Space Science 52: 229-237. doi: 10.1016/j.pss.2003.08.019

Onofri S, Fenice M, Cicalini AR, Tosi S, Magrino A, Pagano S, Selbmann L, Zucconi L, Vishniac HS, Ocampo-Friedmann R, Friedmann FI (2000) Ecology and biology of microfungi from Antarctic rocks and soils. Italian journal of Zoology 67: 163-167. doi: $10.1080 / 11250000009356372$

Onofri S, Pagano S, Zucconi L, Tosi S (1999) Friedmanniomyces endolithicus (Fungi, Hyphomycetes), anam-gen and sp nov, from continental Antarctica. Nova Hedwigia 68: 175-182.

Onofri S, Tosi S, Persiani AM, Maggi O, Riess S, Zucconi L (1992) Mycological researches in Victoria Land terrestrial ecosystems. In: Proceedings of the 2nd Meeting on Biology in Antarctica, Padua, 26-28.

Ruibal C, Gueidan C, Selbmann L, Gorbushina AA, Crous PW, Groenewald JZ, Muggia L, Grube M, Isola D, Schoch CL, Staley JT, Lutzoni F, de Hoog GS (2009) Phylogeny of rock-inhabiting fungi related to Dothideomycetes. Studies in Mycology 64: 123-133. doi: $10.3114 /$ sim.2009.64.06

Scalzi G, Selbmann L, Zucconi L, Rabbow E, Horneck G, Albertano P, Onofri S (2012) LIFE Experiment: Isolation of Cryptoendolithic Organisms from Antarctic Colonized 
Sandstone Exposed to Space and Simulated Mars Conditions on the International Space Station. Origins of Life and Evolution of Biospheres 42: 253-262. doi: 10.1007/s11084012-9282-5

Selbmann L, Turchetti B, Yurkov A, Cecchini C, Zucconi L, Isola D, Buzzini P, Onofri S (2014) Description of Taphrina antarctica f.a. sp nov., a new anamorphic ascomycetous yeast species associated with Antarctic endolithic microbial communities and transfer of four Lalaria species in the genus Taphrina. Extremophiles 18: 707-721. doi: 10.1007/ s00792-014-0651-z

Selbmann L, Isola D, Fenice M, Zucconi L, Sterflinger K, Onofri S (2012) Potential extinction of Antarctic endemic fungal species as a consequence of global warming. Science of the Total Environment 438: 127-134. doi: 10.1016/j.scitotenv.2012.08.027

Selbmann L, Isola D, Zucconi L, Onofri S (2011) Resistance to UV-B induced DNA damage in extreme-tolerant cryptoendolithic Antarctic fungi: detection by PCR assays. Fungal Biology 115: 937-944. doi: 10.1016/j.funbio.2011.02.016

Selbmann L, Zucconi L, Ruisi S, Grube M, Cardinale M, Onofri S (2010) Culturable bacteria associated with Antarctic lichens: affiliation and psychrotolerance. Polar Biology 33: 71-83. doi: 10.1007/s00300-009-0686-2

Tesei D, Marzban G, Zakharova K, Isola D, Selbmann L, Sterflinger K (2012) Alteration of protein patterns in black rock inhabiting fungi as a response to different temperatures. Fungal Biol 116: 932-940. doi: 10.1016/j.funbio.2012.06.004

Zucconi L, Onofri S, Cecchini C, Isola D, Ripa C, Fenice M, Madonna S, Reboleiro-Rivas P, Selbmann L (2014) Mapping the lithic colonization at the boundaries of life in Northern Victoria Land, Antarctica. Polar Biology: 1-12. doi: 10.1007/s00300-014-1624-5

Zucconi L, Selbmann L, Buzzini P, Turchetti B, Guglielmin M, Frisvad JC, Onofri S (2012) Searching for eukaryotic life preserved in Antarctic permafrost. Polar Biology 35: 749757. doi: 10.1007/s00300-011-1119-6

Zucconi L, Pagano S, Fenice M, Selbmann L, Tosi S, Onofri S (1996) Growth temperature preferences of fungal strains from Victoria Land, Antarctica. Polar Biology 16: 53-61. doi: 10.1007/Bf02388735 